\title{
Endoscopic therapy of benign biliary strictures
}

\author{
Joel R Judah, Peter V Draganov
}

\author{
Joel R Judah, Peter V Draganov, University of Florida, Division \\ of Gastroenterology, Hepatology and Nutrition, Gainesville, \\ Florida, United States \\ Correspondence to: Peter Draganov, MD, Division of \\ Gastroenterology, Hepatology and Nutrition, PO Box 100214, \\ University of Florida, Gainesville, FL 32610-0214, \\ United States.dragapv@medicine.ufl.edu \\ Telephone: +1-352-3922877 Fax:+1-352-3923618 \\ Received: 2007-04-23 Accepted: 2007-05-21
}

\begin{abstract}
Benign biliary strictures are being increasingly treated with endoscopic techniques. The benign nature of the stricture should be first confirmed in order to ensure appropriate therapy. Surgery has been the traditional treatment, but there is increasing desire for minimally invasive endoscopic therapy. At present, endoscopy has become the first line approach for the therapy of postliver transplant anastomotic strictures and distal (Bismuth I and II ) post-operative strictures. Strictures related to chronic pancreatitis have proven more difficult to treat, and endoscopic therapy is reserved for patients who are not surgical candidates. The preferred endoscopic approach is aggressive treatment with gradual dilation of the stricture and insertion of multiple plastic stents. The use of uncovered self expandable metal stents should be discouraged due to poor long-term results. Treatment with covered metal stents or bioabsorbable stents warrants further evaluation. This area of therapeutic endoscopy provides an ongoing opportunity for fresh research and innovation.
\end{abstract}

(C) 2007 WJG. All rights reserved.

Key words: Biliary stricture; Endoscopy; Biliary stent; Pancreatitis; Liver transplant; Anastomotic stricture

Judah JR, Draganov PV. Endoscopic therapy of benign biliary strictures. World J Gastroenterol 2007; 13(26): 3531-3539

http://www.wjgnet.com/1007-9327/13/3531.asp

\section{INTRODUCTION}

Therapy of benign biliary strictures can pose great challenge. Surgical repair traditionally has been the preferred approach. Lately with advances in therapeutic endoscopy, there is increased opportunity for endoscopic management. The lack of well designed trials, combined with evolving technology allows opportunity for further advances.

\section{ETIOLOGY}

An understanding of the etiology of the stricture can help guide therapy. The etiology of benign biliary strictures is diverse (Table 1). In Western countries, the most common type is the post-operative stricture. Strictures can occur secondary to intraoperative injury, most commonly during laparoscopic cholecystectomy. Anastomotic strictures are seen following bile duct reconstruction or orthotopic liver transplant $(\mathrm{OLT})^{[1,2]}$. Benign strictures can also occur in the setting of chronic pancreatitis. These strictures often develop within the intrapancreatic portion of the common bile duct ${ }^{[3]}$. A common cause of bile duct stricture in Asia is infection with the fluke, Clonorchis sinensis. While these strictures are benign in nature, they can progress to cholangiocarcinoma. Other causes of benign biliary stricture include primary sclerosing cholangitis, recurrent cholangitis, sarcoidosis, abdominal trauma, ischemic injury, chemotherapy, radiation therapy, HIV cholangiopathy, Mirizzi syndrome, vasculitis in lupus or polyarteritis nodosa, infections such as tuberculosis and histoplasmosis, sphincter of Oddi dysfunction, papillary stenosis, and choledochal cyst.

\section{CLASSIFICATION}

Bismuth et $\mathrm{al}^{\left[{ }^{[4]}\right.}$ in 1978 proposed a classification based on the location of the biliary stricture (Table 2). Bismuth I strictures are located $>2 \mathrm{~cm}$ distal to the confluence of the left and right hepatic ducts (hepatic bifurcation). Type II strictures are located $<2 \mathrm{~cm}$ from the hepatic bifurcation. Bismuth III lesions are present at the bifurcation. Type IV lesions involve the right or left hepatic ducts, while type $\mathrm{V}$ lesions extend into the right or left hepatic branch ducts.

\section{PRESENTATION}

Benign biliary strictures are associated with a broad spectrum of presentations, from subclinical disease with mild elevation in liver function tests to complete hepatic obstruction with jaundice and hyperbilirubinemia. Recurrent cholangitis is a life-threatening complication of biliary strictures. Biliary stones may develop above the stricture and provide a nidus for persistent infection. Chronic low-grade biliary obstruction may have devastating long-term consequences by leading to secondary biliary 


\section{Table 1 Etiologies of benign bile duct strictures}

Surgical

Cholecystectomy (open or laparoscopic)

Biliary anastomosis

Orthotopic liver transplant

Biliary reconstruction

Chronic pancreatitis

Clonorchis sinensis

Primary sclerosing cholangitis

Recurrent cholangitis

Sarcoidosis

Abdominal trauma

Ischemic injury

Chemotherapy

Radiation therapy

HIV cholangiopathy

Mirizzi syndrome

Vasculitis

Infection (e.g. tuberculosis or histoplasmosis)

Sphincter of Oddi dysfunction

Choledochal cyst

\section{Table 2 Bismuth classification for benign biliary strictures}

\begin{tabular}{ll} 
Bismuth classification & Location \\
\hline I & $>2 \mathrm{~cm}$ distal to the hepatic bifurcation \\
II & $<2 \mathrm{~cm}$ distal to the hepatic bifurcation \\
III & At the level of the hepatic bifurcation \\
IV & Involves the right or left hepatic duct \\
V & Extends into the left or right hepatic branch ducts \\
\hline
\end{tabular}

cirrhosis and development of end-stage liver disease ${ }^{[5]}$. Post-operative strictures present at various intervals after the procedure. If the duct was clipped, the patients usually present within days. By contrast, it may take over a year for symptoms to become evident if a stricture develops from heat injury or biliary leak ${ }^{[6]}$. Strictures due to transplantrelated biliary anastamosis have a variable presentation, from a few days to over 2 years after transplantation ${ }^{[7]}$.

\section{DIAGNOSIS AND EVALUATION OF BILIARY STRICTURE}

Before deciding on a therapeutic plan, it is of utmost importance to thoroughly investigate the stricture (Figure 1). Of special interest is to ascertain whether a stricture is benign or malignant. In post-operative patients, the clinical history may be sufficient to ensure the benign nature of the stricture. In cases where there is ambiguity about the etiology of the stricture, further work-up is helpful. Benign strictures tend to have lower alkaline phosphatase and AST levels than malignant strictures ${ }^{[8]}$. Tumor markers, such as carbohydrate antigen $19-9$ with a value greater than $100 \mathrm{U} / \mathrm{mL}$ have been found to be $50 \%-60 \%$ sensitive for cholangiocarcinoma and gallbladder cancer ${ }^{[0]}$. Unfortunately the specificity of this test is very low since carbohydrate antigen 19-9 levels are increased in benign biliary obstruction as well ${ }^{[10]}$. Elevated carcinoembryonic antigen level is present in nearly $40 \%$ patients with pancreatic cancer ${ }^{[11]}$.

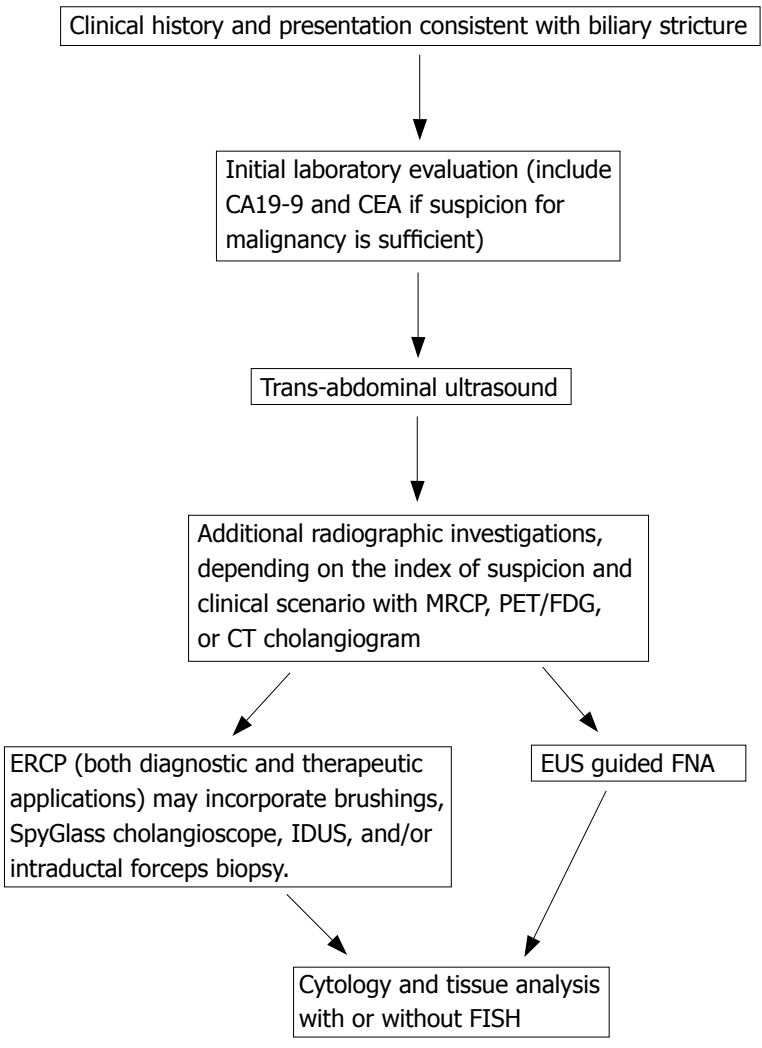

Figure 1 Flow chart demonstrating the diagnostic work-up of biliary strictures.

Trans-abdominal ultrasound is often the first investigation carried out to evaluate biliary strictures. This test usually identifies the presence of an obstruction and may help localize the site of the obstruction. Hepatic scintigraphy with imino-diacetic acid (HIDA) is highly sensitivity in showing an obstructive process, but beyond this provides little additional diagnostic information ${ }^{[12]}$. HIDA scans have been used to confirm improved biliary drainage after treatment of strictures ${ }^{[13]}$. Magnetic resonance cholangio-pancreatography (MRCP) is increasingly utilized to evaluate the biliary tree and help localize a lesion before a therapeutic procedures is undertaken. MRCP is especially useful in high grade strictures, which are difficult to inject with contrast from a proximal duct. MRCP is also useful in patients with a transected duct where opacification of the excluded distal segments is difficult. Helical and multidetector CT scanners have allowed the development of CT cholangiography; however, at the present time this technique is used much less frequently than MRCP. Initial clinical studies suggest a potential role of positron emission tomography (PET) using 2-[18F]fluoro-2-deoxyD-glucose (FDG) in differentiating cholangiocarcinoma from benign disease ${ }^{[14]}$. An additional benefit of radiographic imaging studies is that they provide valuable information about the surrounding structures and organ systems and allow assessment of a more wide-spread disease process involving the biliary tree.

Endoscopic techniques can provide additional diagnostic information about the biliary stricture. Endoscopic retrograde cholangio-pancreatography (ERCP) helps to characterize the stricture by providing 


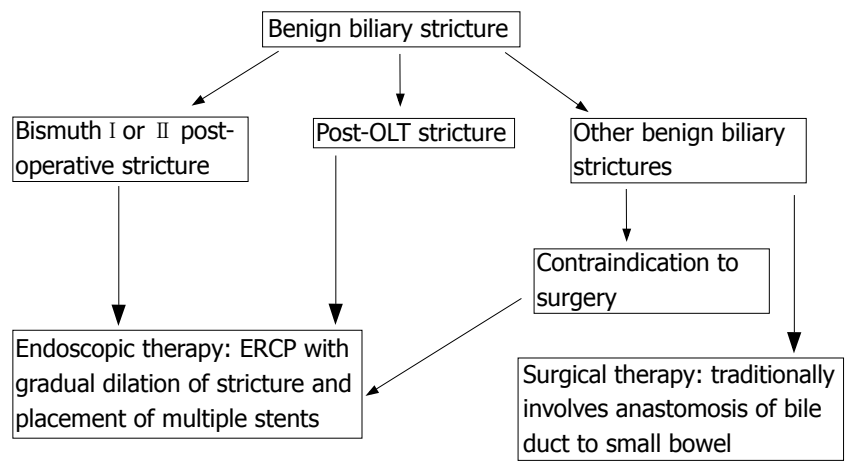

Figure 2 Flow chart demonstrating the therapeutic options for initial treatment of benign biliary strictures.

tissue samples. Although, the sensitivity of bilary fluid and brush cytology is low; the addition of fine needle aspiration biopsy and intraductal forceps biopsy ("triple tissue sampling") improves the sensitivity to about $60 \%{ }^{[15]}$. It has been observed that the addition of fluorescence in situ hybridization (FISH) analysis to routine brush cytology improves the diagnostic accuracy ${ }^{[16]}$. Some recent data shows higher sensitivity and specificity with biliary brush cytology for the diagnosis of cholangiocarcinoma in primary sclerosing cholangitis, with a sensitivity of $70 \%$ to $100 \%$ and specificity of $80 \%$ to $95 \%{ }^{[17]}$. Conflicting data exists as to whether intraductal ultrasonography (IDUS), when used to supplement ERCP, improves the ability to distinguish benign from malignant strictures ${ }^{[18-20]}$. Some studies have shown that IDUS improves the accuracy of ERCP in differentiating malignant from benign strictures to nearly $90 \%{ }^{[21]}$. Endoscopic ultrasound (EUS) with fine needle aspiration (FNA) may also help determine whether the stricture is benign or malignant. Currently, the sensitivity of EUS-FNA for the diagnosis of malignant strictures varies widely, from $43 \%$ to $86 \%{ }^{[22-24]}$. The SpyGlass peroral cholangiopancreatoscopy system is a developing technology that utilizes a fiberoptic cholangioscope passed through a therapeutic duodenoscope, and allows biopsy of the biliary tract under direct vision ${ }^{[25]}$. A recent report in humans showed that its use is indeed clinically feasible ${ }^{[2]}$. The SpyGlass system was evaluated in 35 patients with indeterminate stricture and demonstrated a sensitivity of $71 \%$ and specificity of $100 \%$ in diagnosing malignancy. Prospective multicenter trials are currently underway to further evaluate the SpyGlass system.

\section{TRADITIONAL THERAPY}

Traditionally, surgery has been the treatment of choice for benign extrahepatic bile duct strictures and usually involves creating an anastomosis between the bile duct and the small bowel (Figure 2). A choledocho-jejunostomy or choledocho-duodenostomy is created for distal common bile duct strictures, while a hepatico-jejunostomy is performed for high common bile duct strictures. Complex biliary leaks or transected ducts may require partial hepatectomy or orthotopic liver transplantation. Success rates are upwards of 90\% after surgery involving small bowel anastomosis, and reintervention rates are less than $10 \%{ }^{[27-29]}$. Complications of surgery including side effects of general anesthesia, laparotomy, and extended hospitalization are seen in about $25 \%$ patients $^{[7]}$. Furthermore, recurrent stricture rate varies from 10\% to $45 \%{ }^{[6,30-35]}$. Many patients are poor surgical candidates because of comorbidities and may prefer an initial attempt at less invasive treatment. Endoscopic therapy does not preclude surgery, because if it is unsuccessful, surgery can still be performed. As a result, minimally invasive endoscopic treatment is an attractive option for the management of benign biliary strictures.

\section{ANTIBIOTIC TREATIMENT BEFORE CORRECTIVE THERAPY}

Resistance to bile flow secondary to a biliary stricture follows the Hagen-Poiseuille's law, which states that the resistance to flow in a tube is inversely proportional to the fourth exponent of the tube's radius. Thus, the overall goal of therapy is to increase the radius of the stenosis. According to this law, even small increases in the diameter decrease the resistance significantly. However, until the stenosis is remedied, the static bile provides an excellent culture medium for bacterial growth, and the development of cholangitis. Indeed, nearly $25 \%$ patients with obstructive jaundice have significant bacterobilia ${ }^{[36]}$. Therefore, patients with obstructing lesions should receive prophylactic broadspectrum antibiotics before an endoscopic procedure. The duration of antibiotic prophylaxis is guided by the outcome of the intervention, i.e., whether or not it was successful in relieving the obstruction ${ }^{[37]}$. Adequate choices for antibiotic prophylaxis include piperacillin, cefuroxime, and ciprofloxacin ${ }^{[38,39]}$. Coverage for pseudomonas should be added if local epidemiological data suggests high rates of this infection, or if there is a history of improper disinfection of endoscopes ${ }^{[37]}$. Regardless of the antibiotic therapy, the single most important factor in preventing cholangitis is relief of the obstruction.

\section{ACCESSING THE STRICTURE}

Retrograde cholangiogram is not only difficult to perform in the presence of a tight biliary stricture, but the passage of a guidewire across the stricture becomes quite challenging. Benign strictures, especially those associated with chronic pancreatitis, may be surrounded by dense fibrous tissue. As a result, the introduction of guide wires becomes very difficult. The standard endoscopic dilating device used for traversing strictures is $5 \mathrm{~F}$ in size and is passed over a 0.035 inch guidewire. Several other approaches have been used in such a situation. The $7 \mathrm{~F}$ Soehendra screw-type stent extractor (Cook Medical, Winston Salem, NC) is useful in difficult strictures ${ }^{[38-43]}$. Another technique is to use a $3.3 \mathrm{~F}$ peripheral angioplasty balloon threaded over a 0.018 inch guidewire ${ }^{[4]}$. This balloon inflates to a $6.0 \mathrm{~mm}$ diameter at $16 \mathrm{~atm}$ pressure. A steerable catheter (Autotome Rx, Boston Scientific, Natick, MA), with tapered tip sizes ranging from 3.9F to 4.9F facilitates traversing complex hilar strictures ${ }^{[45]}$. If the 
endoscopic approach is not successful in traversing the stricture, it may become necessary to consider a combined endoscopic and percutaneous approach ${ }^{[46]}$. Regardless of the method used, therapeutic procedures for biliary strictures require a high degree of patient cooperation, and the use of general anesthesia often helps in achieving a successful outcome $e^{[4]}$.

\section{POSTOPERATIVE STRICTURES}

It has been estimated that $0.1 \%$ to $0.2 \%$ of patients develop a biliary stricture after open cholecystectomy ${ }^{[48,49]}$. Since the introduction of laparoscopic cholecystectomy in 1985 , the rates of bile duct injury with resultant stenosis from intraoperative injury have decreased as the surgeons have gained greater experience with the procedure. Currently, the biliary stricture rates vary from $0.2 \%$ to $0.7 \%{ }^{[27,50-53]}$, although some reports indicate figures as high as $2.8 \%{ }^{[54]}$. Biliary complications also occur frequently after orthotopic liver transplantation, with an incidence of around $12 \%-13 \%{ }^{[55,56]}$. One of the most common complications is stricture formation at the choledochocholedochostomy anastomosis. These strictures are the result of a size mismatch between the donor and recipient ducts, and ischemia at the anastomotic site ${ }^{[2]}$.

As mentioned previously, surgical therapy has traditionally been the preferred approach in correcting benign biliary strictures. However, beginning in the 1970's, minimally invasive therapies gained greater acceptance. A report from the Johns Hopkins Hospital on 42 patients, from 1979 to 1987, compared surgical therapy with percutaneous balloon dilation ${ }^{[27]}$. After a 5-year follow-up, recurrence of jaundice or cholangitis were markedly lower in the surgical group (treated with Roux-Y choledocho- or hepaticojejunostomy) compared to balloon dilation $(12 \%$ vs $45 \%$ ). Of note, the total hospital stay and cost associated with therapy were not significantly different between the two groups.

The success rates began to improve with the introduction of endoscopic stenting. The initial clinical data showed short-term benefit from endoscopic therapy. A 1986 case series documented 21 patients who had one or two $10 \mathrm{~F}$ stents placed for benign postoperative stricture ${ }^{[57]}$. After a follow-up of at least $6 \mathrm{mo}, 19$ patients $(90 \%)$ had a good $(14 \%)$ or excellent $(76 \%)$ result. Another report in 1989, described 29 patients with benign postoperative biliary stricture who underwent endoscopic stent placement with a single $7 \mathrm{~F}, 9.5 \mathrm{~F}$, or $11.5 \mathrm{~F}$ stent inserted for a mean of $162 \mathrm{~d}$ before removal ${ }^{[58]}$. During follow-up of $19 \mathrm{mo}, 74 \%$ patients demonstrated successful response to therapy, with $48 \%$ showing an excellent response and $26 \%$ having a good response.

The success of endoscopic treatment for benign postoperative biliary strictures was confirmed by studies with more long-term patient follow-up. A 1989 report ${ }^{[59]}$ on 25 patients who underwent endoscopic balloon dilation with or without stent placement revealed that $88 \%$ patients benefited from the procedure, and none suffered a recurrence of symptoms, stricture formation or elevation of the liver function tests during 4-year followup. Furthermore, there was no significant morbidity or mortality associated with the endoscopic therapy. Another study on 70 patients who received endoscopic stenting for post-operative biliary strictures was published in $1992^{[60]}$. The patients were followed for a mean of $42 \mathrm{mo}$. Outcome assessment revealed that $83 \%$ patients had excellent (defined as remaining asymptomatic with normal or stable liver enzymes) or good results (defined as having only one episode of cholangitis). Thus, these studies revealed that endoscopic therapy offered a safe and effective alternative to surgery for benign biliary strictures.

A direct comparison of surgical and endoscopic therapy was published in 1993, with 66 patients in the endoscopic therapy group and 35 patients in the surgical group $^{[35]}$. This trial was non-randomized and non-blinded, and the type of therapy selected was based on patient and physician preference. Endoscopic therapy consisted of a single $10 \mathrm{~F}$ plastic stent placed after biliary sphincterotomy, followed 6 wk later by exchange with two $10 \mathrm{~F}$ stents. These stents were then changed electively every 3 mo for 1 year. Surgical therapy consisted of biliary-bowel anastomosis, usually hepaticojejunostomy. The mean length of follow-up was 50 mo for the surgery group and 42 mo for the endoscopic group. Early complications occurred more frequently in the surgically treated group $(26 \%$ vs $8 \%)$. Late complications occurred only in the endoscopically treated patients ( $27 \%$ vs $0 \%)$, mostly due to stent occlusion and resultant cholangitis. Recurrent stricture occurred in $17 \%$ of patients in both the surgical and endoscopic groups. These findings suggested that surgery and endoscopy have similar long-term success rate in benign biliary strictures.

A retrospective case-control study on 42 patients with postcholecystectomy stricture revealed similar results with surgery and endoscopic treatment ${ }^{[61]}$. Twenty patients were treated endoscopically with one to three $10 \mathrm{~F}$ to $12 \mathrm{~F}$ stents, while 22 patients received surgery (hepaticojejunostomy, choledochojejunostomy, or intrahepatic cholangiojejunostomy). The patients were followed for at least $60 \mathrm{mo}$. Excellent or good results were achieved in $77 \%$ with surgery vs $80 \%$ with endoscopic treatment, revealing no significant difference in outcome between the two groups. The average length of hospital stay was shorter in the endoscopy group compared with the surgery group (5.8 vs $10.8 \mathrm{~d}$ ). Again, the main complication of the endoscopic group was stent occlusion and cholangitis.

In 2006, a French group published data showing benefit with ERCP-directed therapy for post-laparoscopic cholecystectomy biliary stricture ${ }^{[62]}$. Sixty-five patients had balloon dilatation followed by stent placement (one to four stents per patient, with a mean of 1.6 stents inserted simultaneously and exchanged at approximately 3 mo intervals). Stents remained in place for an average of 14 mo, and patients were followed for 28 additional months after the stents were removed. A success rate of $69 \%$, defined as normal ultrasound and liver function tests, was obtained in this group.

Stent placement is associated with complications that may limit the role of endoscopic therapy. As mentioned previously, there is a significant risk of stent occlusion and subsequent cholangitis. Also, there is a tendency for 
strictures to fibrose around the stent as the time from the initial dilation increases. To avoid these problems, attempts to place multiple stents across the stricture have been made. In theory, multiple stents should permit greater stricture dilation over a longer period of time; thus, preventing restenosis when the stents are removed. Furthermore, the incidence of jaundice and cholangitis should decrease when multiple stents are placed, because even if all the stents become occluded, some bile flow may occur in the spaces between the stents.

A report of 45 patients treated with endoscopic insertion of multiple plastic stents was published in $2001^{[63]}$. After pneumatic dilation of the stricture, the maximum possible number of $10 \mathrm{~F}$ stents based on the tightness of the stricture and the diameter of the bile duct were inserted. As many as 4 stents were placed simultaneously during the index ERCP. Every 3 mo, the stents were exchanged with an increasing number of stents until the stricture was obliterated on an occlusion cholangiogram. Forty patients were able to complete the protocol and were followed for 49 mo. Thirty nine of the 40 patients $(97.5 \%)$ had no recurrence of symptoms related to recurrence of biliary stricture, and liver function tests and ultrasound examinations remained normal. The one patient who developed symptoms experienced 2 episodes of cholangitis but did not have stricture recurrence. Thus, this more aggressive approach with increased numbers of stents placed across strictures may be associated with an improved long-term outcome.

In 2002, further data confirmed that multiple stents allow better success in correcting postoperative benign biliary strictures ${ }^{[64]}$. This study evaluated 29 patients with benign strictures, of which 19 were post-surgical. Patients had balloon dilation and one stent, with the largest diameter technically possible, placed during the index ERCP. At 3 mo intervals, additional stents were placed without removal of the indwelling stents if possible, and additional balloon dilation was performed if necessary. After 12 mo from the index ERCP, all stents were removed, and the patients were followed clinically for 48 mo. In the post-operative stricture group, the treatment was successful in 64\% patients, defined as lack of symptoms, normal alkaline phosphatase and bilirubin, and no evidence of stricture by imaging studies (ERCP or MRCP) if available. Only 2 patients developed mild cholangitis during the follow-up period, and this occurred when the patients had only 1 stent in place. Additionally, the data revealed that the distal post-operative lesions (Bismuth I and II) were associated with better success rate compared with proximal hilar lesions (Bismuth III) (80\% vs $25 \%$ ).

A 2005 report from Hungary documented a series of 20 patients with distal common bile duct strictures related to a previous endoscopic biliary sphincterotomy in the setting of choledocholithiasis ${ }^{[65]}$. The patients underwent endoscopic therapy consisting of sequential insertion of an increasing number of plastic stents every three months, with steadily increasing diameters until the stricture was seen to resolve on cholangiogram. Stents were left in place for an average of $9 \mathrm{mo}$, and the median maximum stent diameter was 20F. Follow-up was performed for an average of $14.5 \mathrm{mo}$, during which time 18 of 20 patients $(90 \%)$ had no stricture recurrence or need for repeat ERCP with stent placement. This study provided additional evidence in favor of sequential stent placement with increasing numbers of biliary stents in the treatment of distal biliary strictures.

\section{POST-OLT STRICTURES}

Because of the high incidence of biliary complications after liver transplantation, an increasing body of data has developed with regard to the treatment of postOLT biliary strictures. A report of 15 patients with postOLT strictures was published in $2000^{[66]}$. ERCP was used to access the stricture for balloon dilation, but no stents were placed. Among patients where ERCP was successful in accessing the stricture, the outcome was considered to be good in 4 (27\%), partial in $3(20 \%)$, and poor in $5(33 \%)$. Thus, this study showed that balloon dilation by itself was not a reliable method for treatment of anastomotic strictures. Greater success was observed when stent placement was used in addition to balloon dilation. For example, a 2003 study $^{[67]}$ on 22 patients with post-OLT anastomotic strictures who were treated endoscopically with stent placement and were followed for $54 \mathrm{mo}$, successful stricture resolution was noted in 20 of $22(90 \%)$. In two patients $(10 \%)$, only partial success was demonstrated. Importantly, there was no long-term failure in any patient.

Further data supporting the use of endoscopic treatment for post-OLT biliary strictures was published in $2006^{[68]}$. A total of 25 patients with anastomotic strictures seen at ERCP were included in the study. Balloon dilation alone was compared with dilatation plus placement of an increasing number of bile duct stents. All patients were followed for a median of 6 mo after conclusion of endoscopic therapy. Endoscopic treatment was technically successful in 22 of 25 patients. Nine patients were treated solely with balloon dilatation and the treatment was initially successful in 8 of $9(89 \%)$ patients. However, recurrent strictures developed in 5 patients $(62 \%)$. In 15 patients, a combination of balloon dilatation and stent placement was utilized, with an increasing number and diameter of stents placed at a median of 4 sessions at 2 mo intervals. In this group, initial success occurred in 13 of $15(87 \%)$ patients, and only 4 of $15(27 \%)$ patients showed stricture recurrence. These 4 patients were successfully treated again with a combination of balloon dilatation and stent placement. These findings confirmed the benefit of combination treatment with balloon dilation followed by an increasing number and diameter of stents placed at intervals of $2-3$ mo.

\section{CHRONIC PANCREATITIS RELATED STRICTURES}

Chronic pancreatitis is a cause of benign stricture of the distal common bile duct in up to $30 \%$ patients $^{[69]}$. Often, these strictures are found incidentally on ERCP and do not cause any symptoms. On other occasions, such strictures 
may result in obstructive jaundice, chronic abdominal pain, abnormal liver function tests, recurrent cholangitis, secondary biliary cirrhosis, and choledocholithiasis ${ }^{[5]}$. Traditionally, surgery is the recommended treatment in such patients. However, many of these patients are not ideal surgical candidates due to malnutrition, chronic liver disease, thrombosis of the splenic or portal veins, and other comorbidities ${ }^{[70]}$. Endoscopic therapy is technically difficult due to dense fibrotic tissue, often associated with calcification around the distal bile duct.

Endoscopic treatment with balloon dilation and the use of a single biliary stent has produced excellent technical success and promising short-term results. However, longterm studies have called into question the benefit of endoscopic therapy, as studies show that only $10 \%-28 \%$ patients remain free of obstructive symptoms after removal of the single plastic stent ${ }^{[6,71-73]}$. An exception to this poor response was a study published in 2000 which also involved placement of a single biliary stent. This study on 25 patients who underwent balloon dilation and stenting demonstrated no recurrence of stricture in 20 of 25 patients $(80 \%)$ over a follow-up period of $32 \mathrm{mo}^{[3]}$.

Other studies have evaluated whether multiple plastic stents allow for greater success. A comparison of single versus multiple stents in the treatment of common bile duct strictures was performed on 12 patients who received an increasing number of stents placed at 3 mo intervals over a $14 \mathrm{mo}$ treatment period ${ }^{[74]}$. A mean of 4.3 stents were placed per patient. The multi-stent group was compared with a group of 34 patients who had single stents placed and changed at 3 to 6 mo intervals. Both groups were followed over a 4 year period, and both groups included patients with evidence of chronic calcific pancreatitis $56 \%$ in the single-stent group and $50 \%$ in the multiple-stent group). At the end of the follow-up period, $92 \%$ patients in the multiple-stent group remained asymptomatic with normal liver function tests. Furthermore, the distal common bile duct diameter was noted to increase from a mean of $1.0 \mathrm{~mm}$ to 3.0 $\mathrm{mm}$ after treatment. In the single-stent group, patients demonstrated no change in the diameter of the common bile duct stenosis, $38 \%$ of the group had persistent liver function test abnormalities, $41 \%$ required surgical choledochoduodenostomy, and 9\% died of complications related to liver disease.

A Hungarian study evaluated 29 patients with common bile duct stricture due to chronic calcifying pancreatitis ${ }^{755}$. These patients received the maximum possible number of stents whenever the stents were changed (electively at 3 mo intervals or sooner if stent change was indicated). The patients received a mean of 2.4 stents with a range between 1 and 5 stents. Eighteen patients $(60 \%)$ had complete radiologic and serologic recovery during 1 year follow-up after a mean stenting time of $21 \mathrm{mo}$. Five patients (16\%) continued to require stent placements despite a mean stenting time of $26 \mathrm{mo}$. Three patients $(10 \%)$ required surgery, and 3 patients died ( 1 of unrelated causes and 2 with septic shock of biliary origin). This study again showed a higher rate of success with increasing number of stents.

Nine patients with chronic pancreatitis-induced biliary strictures were included in the previously mentioned 2002 study detailing long-term outcome of benign biliary strictures treated with multiple stent insertions ${ }^{[6]]}$. The overall success rate during the 48 mo follow-up was only $44 \%$. However, all 3 patients without pancreatic head calcifications were treated successfully, while only 1 of 6 patients with pancreatic calcification had a positive response to therapy. This data suggests that pancreatic calcification poses an important therapeutic challenge; however, the small number of patients enrolled in the study makes it difficult to draw firm conclusions.

\section{METAL STENTS}

Metal stents have been employed in an effort reduce stricture recurrence and to maintain duct patency. Traditional open-mesh metal stents are associated with several flaws, including occlusion, stone formation, and lack of permanency ${ }^{[76]}$. Epithelial hyperplasia has also been noted in the bile duct in response to open-mesh metal stents. This results in the stent becoming embedded within the wall of the duct and may lead to a chronic inflammatory process, which could theoretically predispose the patient to an increased risk of cholangiocarcinoma ${ }^{[77]}$. Furthermore, surgical management of patients with metallic stents extending into the intrahepatic ducts is difficult and may require partial hepatectomy or even liver transplantation. These drawbacks of metal stents have traditionally limited their use in benign biliary strictures.

The first use of metal mesh stents in benign strictures was reported in 1990, when radiologists placed bare metal stents percutaneously in 17 patients with postoperative stricture $^{[78]}$. Fourteen of the 17 patients had failed prior attempts at surgical repair, and all 17 patients had failed serial balloon dilations. The metal stents allowed the majority $(82 \%)$ of patients to be free of jaundice or cholangitis during a mean follow-up of 8 mo. There were no major complications or deaths during that time.

Metal stents have also been used in benign strictures resulting from chronic pancreatitis. A study on 20 patients with chronic pancreatitis and evidence of biliary obstruction was reported in $1994^{[79]}$. Eleven of these patients had failed treatment with plastic stents. All 20 patients had persistent cholestasis, seven patients had jaundice, and three overt cholangitis. After placement of uncovered self-expanding metal mesh stents, $90 \%$ patients had relief of jaundice and cholangitis at completion of the follow-up period (mean of $33 \mathrm{mo}$ ). In another study, 13 patients with chronic pancreatitis-related strictures who had previously shown a poor response to plastic stents received uncovered self-expanding metal ${ }^{[80]}$. After a mean follow-up of $50 \mathrm{mo}, 9$ patients $(69 \%)$ were considered to have a successful response; 4 of the 9 patients required another procedure due to stent occlusion during the follow-up period. Therapy during the repeat procedure consisted of insertion of a second metal stent within the lumen of the first stent ( 3 cases) or balloon pull-through for removal of sludge (1 case). The four unsuccessful cases had stent occlusion in 3 cases and stent migration in one case, which were not amenable to endoscopic treatment. 
Another group of 14 patients with symptomatic common bile duct stenosis associated with chronic pancreatitis, were treated with partially covered metal stents after failing plastic stents ${ }^{[81]}$. All patients responded initially with resolution of cholangitis and improvement of cholestasis. However, stent patency rate decreased over time, from $100 \%$ at $12 \mathrm{mo}$ to $40 \%$ at $24 \mathrm{mo}$ and $37.5 \%$ at $36 \mathrm{mo}$. Thus, partially covered metal stents are effective in the initial treatment of strictures, but long term success is limited due to problems with stent patency.

The disadvantages of uncovered metal stents have led to the use of covered metal stents, with the potential benefit that these stents can be removed. In the canine biliary tract, covered metal stents did not induce epithelial hypertrophy and did not become embedded in the bile duct epithelium, unlike bare metal stents ${ }^{[76]}$. The ability to remove a covered Wallstent ${ }^{\mathrm{TM}}$ (Boston Scientific, Natick, MA) several months after placement was shown in 2004, when 13 of such stents were successfully removed endoscopically at a single session after a mean duration of 4.5 mo. By contrast, 4 patients with uncovered metal Wallstents required multiple endoscopic sessions in order to remove the stents in a piecemeal fashion. It is possible that the self-expanding covered metal stents also serve as potential dilators. However, the use of covered metal stents needs further evaluation to determine their therapeutic effectiveness.

\section{BIOABSORBABLE STENTS}

Self-expanding stents made of bioabsorbable material may offer several advantages compared to the plastic and selfexpanding metal stents ${ }^{[82,83]}$. Studies in porcine models show that these stents offer improved patency because of their large diameter, lower biofilm accumulation and reduced incidence of bile duct proliferative changes. Furthermore, patients do not have to undergo additional procedures to remove the stents. Bioabsorbable stents can be impregnated with pharmaceutical compounds, such as antimicrobial and antineoplastic agents. The stent's underlying biological structure can be used as a reservoir for drug-elution and to control elution kinetics. The biological stents may provide the necessary framework for bioengineered tissue culture and/or extra-cellular matrix for treatment of strictures. However, these stents remains investigational at the present time.

\section{CONCLUSION}

Therapeutic endoscopy plays an important role in the treatment of benign biliary strictures. Despite the lack of randomized controlled trials, endoscopy has become the first line therapy for post-liver transplant anastomotic strictures and distal (Bismuth I and III) post-operative strictures. Strictures related to chronic pancreatitis have proven more difficult to treat, and endoscopic therapy is reserved for patients who are not surgical candidates. At present, the preferred endoscopic approach is aggressive dilation of the stricture and insertion of multiple plastic stents. The use of uncovered self expanding metal stents should be discouraged due to poor long-term results.
Covered metal stents or even bioabsorbable stents may provide superior results and deserve further investigation. The area of therapeutic endoscopy will continue to evolve and offer opportunities for innovative new techniques.

\section{COMMENTS}

\section{Background}

Endoscopic techniques are being increasingly utilized in the treatment of benign biliary strictures. More research related to the endoscopic therapy of these strictures is underway. Thus, a review is necessary to stay abreast of the latest developments in this area.

\section{Research frontiers}

Surgery has been the traditional treatment for benign biliary strictures, but therapeutic endoscopy is finding an increasing role in the treatment of such strictures.

\section{Innovations and breakthroughs}

Endoscopic techniques have become the first line approach for the treatment of post-OLT anastomotic and distal (Bismuth I and II ) post-operative strictures. The current preferred endoscopic approach involves gradual dilation of the stricture and insertion of multiple plastic stents. Preliminary data describing the use of covered metal stents and bioabsorbable stents is promising and warrants further investigation.

\section{Applications}

The present review will allow readers to become familiar with the current status of endoscopic therapy in benign biliary strictures.

\section{Peer review}

This is a comprehensive review of the literature involving endoscopic therapy of benign biliary strictures.

\section{REFERENCES}

1 Martin RF, Rossi RL. Bile duct injuries. Spectrum, mechanisms of injury, and their prevention. Surg Clin North Am 1994; 74: 781-803; discussion 805-807

2 Porayko MK, Kondo M, Steers JL. Liver transplantation: late complications of the biliary tract and their management. Semin Liver Dis 1995; 15: 139-155

3 Vitale GC, Reed DN, Nguyen CT, Lawhon JC, Larson GM. Endoscopic treatment of distal bile duct stricture from chronic pancreatitis. Surg Endosc 2000; 14: 227-231

4 Bismuth $\mathbf{H}$. Postoperative strictures of the bile duct. In: Blumgart LH, ed. The Biliary Tract. Edinburgh: Churchill Livingstone, 1982: 209-218

5 Warshaw AL, Schapiro RH, Ferrucci JT, Galdabini JJ. Persistent obstructive jaundice, cholangitis, and biliary cirrhosis due to common bile duct stenosis in chronic pancreatitis. Gastroenterology 1976; 70: 562-567

6 Bergman JJ, van den Brink GR, Rauws EA, de Wit L, Obertop H, Huibregtse K, Tytgat GN, Gouma DJ. Treatment of bile duct lesions after laparoscopic cholecystectomy. Gut 1996; 38: 141-147

7 Davidson BR, Rai R, Nandy A, Doctor N, Burroughs A, Rolles K. Results of choledochojejunostomy in the treatment of biliary complications after liver transplantation in the era of nonsurgical therapies. Liver Transpl 2000; 6: 201-206

8 Al-Mofleh IA, Aljebreen AM, Al-Amri SM, Al-Rashed RS, AlFaleh FZ, Al-Freihi HM, Abdo AA, Isnani AC. Biochemical and radiological predictors of malignant biliary strictures. World J Gastroenterol 2004; 10: 1504-1507

9 Patel AH, Harnois DM, Klee GG, LaRusso NF, Gores GJ. The utility of CA 19-9 in the diagnoses of cholangiocarcinoma in patients without primary sclerosing cholangitis. Am J Gastroenterol 2000; 95: 204-207 
10 Mann DV, Edwards R, Ho S, Lau WY, Glazer G. Elevated tumour marker CA19-9: clinical interpretation and influence of obstructive jaundice. Eur J Surg Oncol 2000; 26: 474-479

11 Duraker N, Hot S, Polat Y, Höbek A, Gençler N, Urhan N. CEA, CA 19-9, and CA 125 in the differential diagnosis of benign and malignant pancreatic diseases with or without jaundice. J Surg Oncol 2007; 95: 142-147

12 Kloiber R, AuCoin R, Hershfield NB, Logan K, Molnar CP, Blair KM, Shaffer EA. Biliary obstruction after cholecystectomy: diagnosis with quantitative cholescintigraphy. Radiology 1988; 169: 643-647

13 Krishnamurthy GT, Turner FE. Pharmacokinetics and clinical application of technetium 99m-labeled hepatobiliary agents. Semin Nucl Med 1990; 20: 130-149

14 Prytz H, Keiding S, Björnsson E, Broomé U, Almer S, Castedal M, Munk OL. Dynamic FDG-PET is useful for detection of cholangiocarcinoma in patients with PSC listed for liver transplantation. Hepatology 2006; 44: 1572-1580

15 Jailwala J, Fogel EL, Sherman S, Gottlieb K, Flueckiger J, Bucksot LG, Lehman GA. Triple-tissue sampling at ERCP in malignant biliary obstruction. Gastrointest Endosc 2000; 51: 383-390

16 Kipp BR, Stadheim LM, Halling SA, Pochron NL, Harmsen S, Nagorney DM, Sebo TJ, Therneau TM, Gores GJ, de Groen PC, Baron TH, Levy MJ, Halling KC, Roberts LR. A comparison of routine cytology and fluorescence in situ hybridization for the detection of malignant bile duct strictures. Am J Gastroenterol 2004; 99: 1675-1681

17 Boberg KM, Jebsen P, Clausen OP, Foss A, Aabakken L, Schrumpf E. Diagnostic benefit of biliary brush cytology in cholangiocarcinoma in primary sclerosing cholangitis. J Hepatol 2006; 45: 568-574

18 Gress F, Chen YK, Sherman S, Savides T, Zaidi S, Jaffe P, Lehman G, Wonn MJ, Hawes R. Experience with a catheterbased ultrasound probe in the bile duct and pancreas. Endoscopy 1995; 27: 178-184

19 Inui K, Nakazawa S, Yoshino J, Wakabayashi T, Okushima K, Nakamura Y, Hattori T, Miyoshi H. Ultrasound probes for biliary lesions. Endoscopy 1998; 30 Suppl 1: A120-A123

20 Tamada K, Nagai H, Yasuda $Y$, Tomiyama T, Ohashi A, Wada S, Kanai N, Satoh Y, Ido K, Sugano K. Transpapillary intraductal US prior to biliary drainage in the assessment of longitudinal spread of extrahepatic bile duct carcinoma. Gastrointest Endosc 2001; 53: 300-307

21 Domagk D, Wessling J, Reimer P, Hertel L, Poremba C, Senninger N, Heinecke A, Domschke W, Menzel J. Endoscopic retrograde cholangiopancreatography, intraductal ultrasonography, and magnetic resonance cholangiopancreatography in bile duct strictures: a prospective comparison of imaging diagnostics with histopathological correlation. Am J Gastroenterol 2004; 99: 1684-1689

22 DeWitt J, Misra VL, Leblanc JK, McHenry L, Sherman S. EUSguided FNA of proximal biliary strictures after negative ERCP brush cytology results. Gastrointest Endosc 2006; 64: 325-333

23 Rösch T, Hofrichter K, Frimberger E, Meining A, Born P, Weigert N, Allescher HD, Classen M, Barbur M, Schenck U, Werner M. ERCP or EUS for tissue diagnosis of biliary strictures? A prospective comparative study. Gastrointest Endosc 2004; 60: 390-396

24 Eloubeidi MA, Chen VK, Jhala NC, Eltoum IE, Jhala D, Chhieng DC, Syed SA, Vickers SM, Mel Wilcox C. Endoscopic ultrasound-guided fine needle aspiration biopsy of suspected cholangiocarcinoma. Clin Gastroenterol Hepatol 2004; 2: 209-213

25 Chen YK. Preclinical characterization of the Spyglass peroral cholangiopancreatoscopy system for direct access, visualization, and biopsy. Gastrointest Endosc 2007; 65: 303-311

26 Chen YK, Pleskow DK. SpyGlass single-operator peroral cholangiopancreatoscopy system for the diagnosis and therapy of bile-duct disorders: a clinical feasibility study (with video). Gastrointest Endosc 2007; 65: 832-841

27 Pitt HA, Kaufman SL, Coleman J, White RI, Cameron JL. Benign postoperative biliary strictures. Operate or dilate? Ann Surg 1989; 210: 417-425; discussion 426-427
28 Lillemoe KD, Melton GB, Cameron JL, Pitt HA, Campbell KA, Talamini MA, Sauter PA, Coleman J, Yeo CJ. Postoperative bile duct strictures: management and outcome in the 1990s. Ann Surg 2000; 232: 430-441

29 Quintero GA, Patiño JF. Surgical management of benign strictures of the biliary tract. World J Surg 2001; 25: 1245-1250

30 Ross CB, H'Doubler WZ, Sharp KW, Potts JR. Recent experience with benign biliary strictures. Am Surg 1989; 55: 64-70

31 Böttger T, Junginger T. Long-term results after surgical treatment of iatrogenic injury of the bile ducts. Eur J Surg 1991; 157: $477-480$

32 Frattaroli FM, Reggio D, Guadalaxara A, Illomei G, Pappalardo G. Benign biliary strictures: a review of 21 years of experience. J Am Coll Surg 1996; 183: 506-513

33 Millis JM, Tompkins RK, Zinner MJ, Longmire WP, Roslyn JJ. Management of bile duct strictures. An evolving strategy. Arch Surg 1992; 127: 1077-1082; discussion 1082-1084

34 Genest JF, Nanos E, Grundfest-Broniatowski S, Vogt D, Hermann RE. Benign biliary strictures: an analytic review (1970 to 1984). Surgery 1986; 99: 409-413

35 Davids PH, Tanka AK, Rauws EA, van Gulik TM, van Leeuwen DJ, de Wit LT, Verbeek PC, Huibregtse K, van der Heyde MN, Tytgat GN. Benign biliary strictures. Surgery or endoscopy? Ann Surg 1993; 217: 237-243

36 Kuzu MA, Kale IT, Cöl C, Tekeli A, Tanik A, Köksoy C. Obstructive jaundice promotes bacterial translocation in humans. Hepatogastroenterology 1999; 46: 2159-2164

37 Motte S, Deviere J, Dumonceau JM, Serruys E, Thys JP, Cremer M. Risk factors for septicemia following endoscopic biliary stenting. Gastroenterology 1991; 101: 1374-1381

38 Mehal WZ, Culshaw KD, Tillotson GS, Chapman RW. Antibiotic prophylaxis for ERCP: a randomized clinical trial comparing ciprofloxacin and cefuroxime in 200 patients at high risk of cholangitis. Eur J Gastroenterol Hepatol 1995; 7 841-845

39 Westphal JF, Brogard JM. Biliary tract infections: a guide to drug treatment. Drugs 1999; 57: 81-91

40 van Someren RN, Benson MJ, Glynn MJ, Ashraf W, Swain $\mathrm{CP}$. A novel technique for dilating difficult malignant biliary strictures during therapeutic ERCP. Gastrointest Endosc 1996; 43: 495-498

41 Baron TH, Morgan DE. Dilation of a difficult benign pancreatic duct stricture using the Soehendra stent extractor. Gastrointest Endosc 1997; 46: 178-180

42 Ziebert JJ, DiSario JA. Dilation of refractory pancreatic duct strictures: the turn of the screw. Gastrointest Endosc 1999; 49 632-635

43 Brand B, Thonke F, Obytz S, Binmoeller KF, Rathod V, Seitz U, Bohnacker S, Jäckle S, Soehendra N. Stent retriever for dilation of pancreatic and bile duct strictures. brand@uke.unihamburg.de. Endoscopy 1999; 31: 142-145

44 Freeman ML, Cass OW, Dailey J. Dilation of high-grade pancreatic and biliary ductal strictures with small-caliber angioplasty balloons. Gastrointest Endosc 2001; 54: 89-92

45 Fazel A, Draganov P, Moezardalan K, Kalaghchi B, Forsmark C. Navigating the hilum: Utility of a steerable catheter for selective cannulation of the intrahepatic bile ducts. Gastrointest Endosc 2005; 61: AB204

46 Hunt JB, Sayer JM, Jacyna M, Crofton M, Summerfield JA. Combined percutaneous transhepatic and endoscopic placement of biliary stents. Surg Oncol 1993; 2: 293-298

47 Martindale SJ. Anaesthetic considerations during endoscopic retrograde cholangiopancreatography. Anaesth Intensive Care 2006; 34: 475-480

48 Roslyn JJ, Binns GS, Hughes EF, Saunders-Kirkwood K, Zinner MJ, Cates JA. Open cholecystectomy. A contemporary analysis of 42,474 patients. Ann Surg 1993; 218: 129-137

49 Deziel DJ. Complications of cholecystectomy. Incidence, clinical manifestations, and diagnosis. Surg Clin North Am 1994; 74: 809-823

50 A prospective analysis of 1518 laparoscopic cholecystectomies. The Southern Surgeons Club. N Engl J Med 1991; 324: 1073-1078 
51 Orlando R, Russell JC, Lynch J, Mattie A. Laparoscopic cholecystectomy. A statewide experience. The Connecticut Laparoscopic Cholecystectomy Registry. Arch Surg 1993; 128: 494-498; discussion 498-499

52 Wherry DC, Marohn MR, Malanoski MP, Hetz SP, Rich NM. An external audit of laparoscopic cholecystectomy in the steady state performed in medical treatment facilities of the Department of Defense. Ann Surg 1996; 224: 145-154

53 Adamsen S, Hansen OH, Funch-Jensen P, Schulze S, Stage JG, Wara P. Bile duct injury during laparoscopic cholecystectomy: a prospective nationwide series. J Am Coll Surg 1997; 184: 571-578

54 Windsor JA, Pong J. Laparoscopic biliary injury: more than a learning curve problem. Aust N Z J Surg 1998; 68: 186-189

55 Lerut J, Gordon RD, Iwatsuki S, Esquivel CO, Todo S, Tzakis A, Starzl TE. Biliary tract complications in human orthotopic liver transplantation. Transplantation 1987; 43: 47-51

56 Greif F, Bronsther OL, Van Thiel DH, Casavilla A, Iwatsuki S, Tzakis A, Todo S, Fung JJ, Starzl TE. The incidence, timing, and management of biliary tract complications after orthotopic liver transplantation. Ann Surg 1994; 219: 40-45

57 Huibregtse K, Katon RM, Tytgat GN. Endoscopic treatment of postoperative biliary strictures. Endoscopy 1986; 18: 133-137

58 Berkelhammer C, Kortan P, Haber GB. Endoscopic biliary prostheses as treatment for benign postoperative bile duct strictures. Gastrointest Endosc 1989; 35: 95-101

59 Geenen DJ, Geenen JE, Hogan WJ, Schenck J, Venu RP, Johnson GK, Jackson A. Endoscopic therapy for benign bile duct strictures. Gastrointest Endosc 1989; 35: 367-371

60 Davids PH, Rauws EA, Coene PP, Tytgat GN, Huibregtse K. Endoscopic stenting for post-operative biliary strictures. Gastrointest Endosc 1992; 38: 12-18

61 Tocchi A, Mazzoni G, Liotta G, Costa G, Lepre L, Miccini M, De Masi E, Lamazza MA, Fiori E. Management of benign biliary strictures: biliary enteric anastomosis vs endoscopic stenting. Arch Surg 2000; 135: 153-157

62 Kassab C, Prat F, Liguory C, Meduri B, Ducot B, Fritsch J, Choury AD, Pelletier G. Endoscopic management of post-laparoscopic cholecystectomy biliary strictures. Long-term outcome in a multicenter study. Gastroenterol Clin Biol 2006; 30: 124-129

63 Costamagna G, Pandolfi M, Mutignani M, Spada C, Perri V. Long-term results of endoscopic management of postoperative bile duct strictures with increasing numbers of stents. Gastrointest Endosc 2001; 54: 162-168

64 Draganov P, Hoffman B, Marsh W, Cotton P, Cunningham J. Long-term outcome in patients with benign biliary strictures treated endoscopically with multiple stents. Gastrointest Endosc 2002; 55: 680-686

65 Pozsár J, Sahin P, László F, Topa L. Endoscopic treatment of sphincterotomy-associated distal common bile duct strictures by using sequential insertion of multiple plastic stents. Gastrointest Endosc 2005; 62: 85-91

66 Schwartz DA, Petersen BT, Poterucha JJ, Gostout CJ. Endoscopic therapy of anastomotic bile duct strictures occurring after liver transplantation. Gastrointest Endosc 2000; 51: 169-174

67 Morelli J, Mulcahy HE, Willner IR, Cunningham JT, Draganov P. Long-term outcomes for patients with post-liver transplant anastomotic biliary strictures treated by endoscopic stent placement. Gastrointest Endosc 2003; 58: 374-379

68 Zoepf T, Maldonado-Lopez EJ, Hilgard P, Malago M, Broelsch
CE, Treichel U, Gerken G. Balloon dilatation vs. balloon dilatation plus bile duct endoprostheses for treatment of anastomotic biliary strictures after liver transplantation. Liver Transpl 2006; 12: 88-94

69 Devière J, Devaere S, Baize M, Cremer M. Endoscopic biliary drainage in chronic pancreatitis. Gastrointest Endosc 1990; 36: 96-100

70 Stahl TJ, Allen MO, Ansel HJ, Vennes JA. Partial biliary obstruction caused by chronic pancreatitis. An appraisal of indications for surgical biliary drainage. Ann Surg 1988; 207: 26-32

71 Barthet M, Bernard JP, Duval JL, Affriat C, Sahel J. Biliary stenting in benign biliary stenosis complicating chronic calcifying pancreatitis. Endoscopy 1994; 26: 569-572

72 Smits ME, Rauws EA, van Gulik TM, Gouma DJ, Tytgat GN, Huibregtse K. Long-term results of endoscopic stenting and surgical drainage for biliary stricture due to chronic pancreatitis. Br J Surg 1996; 83: 764-768

73 Cahen DL, van Berkel AM, Oskam D, Rauws EA, Weverling GJ, Huibregtse K, Bruno MJ. Long-term results of endoscopic drainage of common bile duct strictures in chronic pancreatitis. Eur J Gastroenterol Hepatol 2005; 17: 103-108

74 Catalano MF, Linder JD, George S, Alcocer E, Geenen JE. Treatment of symptomatic distal common bile duct stenosis secondary to chronic pancreatitis: comparison of single vs. multiple simultaneous stents. Gastrointest Endosc 2004; 60: 945-952

75 Pozsár J, Sahin P, László F, Forró G, Topa L. Medium-term results of endoscopic treatment of common bile duct strictures in chronic calcifying pancreatitis with increasing numbers of stents. J Clin Gastroenterol 2004; 38: 118-123

76 Silvis SE, Sievert CE, Vennes JA, Abeyta BK, Brennecke LH. Comparison of covered versus uncovered wire mesh stents in the canine biliary tract. Gastrointest Endosc 1994; 40: 17-21

77 Lopez RR, Cosenza CA, Lois J, Hoffman AL, Sher LS, Noguchi $\mathrm{H}$, Pan SH, McMonigle M. Long-term results of metallic stents for benign biliary strictures. Arch Surg 2001; 136: 664-669

78 Rossi P, Bezzi M, Salvatori FM, Maccioni F, Porcaro ML. Recurrent benign biliary strictures: management with selfexpanding metallic stents. Radiology 1990; 175: 661-665

79 Deviere J, Cremer M, Baize M, Love J, Sugai B, Vandermeeren A. Management of common bile duct stricture caused by chronic pancreatitis with metal mesh self expandable stents. Gut 1994; 35: 122-126

80 van Berkel AM, Cahen DL, van Westerloo DJ, Rauws EA, Huibregtse K, Bruno MJ. Self-expanding metal stents in benign biliary strictures due to chronic pancreatitis. Endoscopy 2004; 36: $381-384$

81 Cantù $\mathbf{P}$, Hookey LC, Morales $\mathrm{A}$, Le Moine $\mathrm{O}$, Devière J. The treatment of patients with symptomatic common bile duct stenosis secondary to chronic pancreatitis using partially covered metal stents: a pilot study. Endoscopy 2005; 37: 735-739

82 Ginsberg G, Cope C, Shah J, Martin T, Carty A, Habecker P, Kaufmann C, Clerc C, Nuutinen JP, Törmälä P. In vivo evaluation of a new bioabsorbable self-expanding biliary stent. Gastrointest Endosc 2003; 58: 777-784

83 Meng B, Wang J, Zhu N, Meng QY, Cui FZ, Xu YX. Study of biodegradable and self-expandable PLLA helical biliary stent in vivo and in vitro. J Mater Sci Mater Med 2006; 17: 611-617

S- Editor Liu Y L- Editor Anand BS E- Editor Wang HF 